\title{
STUDY AND APPLICATION OF REACTIVE ION ETCHING ON GaInP/InGaAs/GaInP QUANTUM-WELL HEMTs
}

\author{
C. W. KUO', Y. K. SU' ${ }^{1}$, H. H. LIN ${ }^{2}$ and C. Y. TSIA ${ }^{1}$ \\ ${ }^{1}$ Department of Electrical Engineering, National Cheng Kung University, 1 University Road, \\ Tainan 70101, Taiwan, R.O.C. \\ ${ }^{2}$ Department of Electrical Engineering, National Taiwan University, Taipei, Taiwan, R.O.C.
}

(Received 31 October 1997; in revised form 19 January 1998)

\begin{abstract}
The gate recessing of a GaInP/InGaAs/GaInP quantum-well HEMT (QHEMT) using pure $\mathrm{BCl}_{3}$ plasma is found improved by the addition of an appropriate amount of $\mathrm{Ar}$ to the gas flow. The influence of $\mathrm{BCl}_{3} / \mathrm{Ar}$ gas flow ratio on GaAs to GaInP etch selectivity, surface roughness and surface damage was determined. These results indicate that the conditions for minimum surface roughness, as determined by atomic force microscopy, corresponded with the conditions for minimum plasma damage, as determine by Raman spectroscopy. The best $\mathrm{BCl}_{3} / \mathrm{Ar}$ gas flow ratio for minimum surface damage and roughness was found to be $6: 4$ at a pressure of $60 \mathrm{mTorr}$ with a $100 \mathrm{~W}$ RF power at this study. Two $\mathrm{BCl}_{3}$ :Ar flow rate ratios, 6:4 and 10:0 (pure $\mathrm{BCl}_{3}$ ) were used to etch the gate recess in $\mathrm{GaInP} / \mathrm{InGaAs} / \mathrm{GaInP}$ QHEMT. From $C-V$ measurements, it is found that the plasma-induced damage of the sample $\mathrm{S}_{6: 4}$ dry-etch with $6: 4 \mathrm{BCl}_{3} / \mathrm{Ar}$ is less than that of the sample $\mathrm{S}_{10: 0}$ dry-etched with pure $\mathrm{BCl}_{3}$. The d.c. characteristics of $\mathrm{S}_{6: 4}$ device was found to be superior to those of the wetetched sample $S_{\text {wet }}$ and $S_{10: 0}$. In addition, the threshold voltage uniformity of sample $S_{6: 4}$ was found to be better than that of sample $S_{\text {wet }}$ and sample $S_{10: 0}$. (C) 1998 Published by Elsevier Science Ltd. All rights reserved
\end{abstract}

\section{INTRODUCTION}

Conventional $\mathrm{N}-\mathrm{AlGaAs} / \mathrm{GaAs}$ HEMTs and $\mathrm{N}-$ AlGaAs/InGaAs/GaAs pseudomorphic HEMTs (PHEMTs) are already available commercially and are already widely used in satellite communication[1]. However, the well-known donor-related deep level traps (i.e. the so call DX centers), that exist in AlGaAs/GaAs HEMTs and AlGaAs/ InGaAs/GaAs PHEMTs, degrade the performance of these devices significantly. Recently, it has been shown that by using the lattice matched GaInP to replace conventional $\mathrm{AlGaAs}$ as the barrier layer, one can improve the performance of the GaAs based HEMTs. It was found that, at low temperatures, no current collapse and no threshold shift were observed for the $\mathrm{InGaP} / \mathrm{GaAs}$ HEMTs. Because no $\mathrm{Al}$ is involved in this material system, the problem associated with $\mathrm{Al}$ oxidation can be avoided in InGaP/GaAs HEMTs[2]. A good Schottky contact can also be formed easily on top of the InGaP barrier layer. Thus, one can expect a good electrical characteristic from the $\mathrm{InGaP} / \mathrm{GaAs}$ HEMTs. High quality $\mathrm{N}-\mathrm{InGaP} / \mathrm{InGaAs} / \mathrm{GaAs}$ PHEMTs were also realized for low noise amplifiers[3].

Plasma etching of compound semiconductors is a key technology for producing high-speed devices. However, plasma-induced damage often results in degrading device performance, such as increased junction leakage and threshold voltage shifts, thereby limiting the use of plasma etching techniques in nanometric fabrication[4,5]. Thus, the study of plasma etching techniques with high selectivity of GaAs to GaInP, as well as the study of related plasma-induced surface damage, are important. Accordingly, a reactive-ion-etching (RIE) process based on $\mathrm{BCl}_{3} / \mathrm{Ar}$ plasma[6-8], that has a good selectivity of GaAs to GaInP, was applied as a gate-recessing technique in the fabrication of $\mathrm{GaInP} / \mathrm{InGaAs} / \mathrm{GaInP}$ quantum-well HEMTs. In order to achieve a plasma with high etching selectivity and low damage, we systematically changed the mixing ratio between $\mathrm{BCl}_{3}$ and Ar to obtain the optimal plasma conditions. In addition, we were also interested in surface damage after plasma bombardment. Raman spectroscopy was used to characterize the damage introduced by plasma etching in the region of and just below the surface of the GaInP barrier layer. Quantitative information about the absolute magnitude of processing-induced disorder is difficult to obtain from Raman spectra. However, the comparison of intensities of the RIE processing induced Raman modes with those of the unetched GaInP can provide information concerning the relative degrees of disorder. Our results show that Raman spectroscopy can be a powerful tool for characterizing the surface region modifications introduced by the plasma processing of semiconductors. Since Raman measurements are nondestructive and require no 


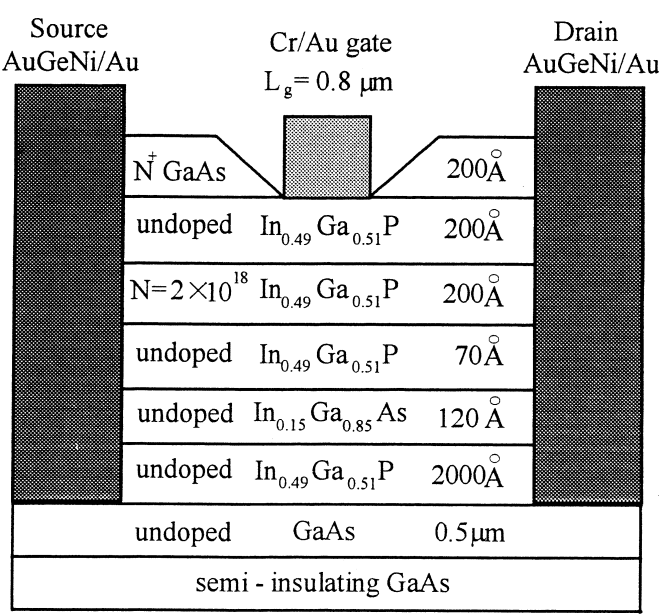

Fig. 1. Schematic representation of the $\mathrm{GaInP} / \mathrm{InGaAs} /$ GaInP quantum-well HEMT (QHEMT).

special sample preparation, they can be made in any environment[9]. Furthermore, atomic force microscopy (AFM) was used to the study the surface morphology which is not possible with a scanning electron microscope (SEM) or by means of surface profilometry for very small feature sizes[10].

Based on our experimentally determined optimum flow rate for $\mathrm{BCl}_{3}+\mathrm{Ar}$ and flow rate for pure $\mathrm{BCl}_{3}$, which used for gate recessing of $\mathrm{GaInP} /$ InGaAs/GaInP QHEMT are compared. $C-V$ measurement was also applied to investigate the plasma-induced surface damage. The d.c. performance and threshold voltage uniformity of RIE-processed devices were compared with high-selectivity wet-etched devices.

\section{EXPERIMENT}

The epitaxial layer used in this study was grown by a gas-source molecular beam epitaxy (GSMBE) system on a semi-insulating GaAs substrate. The structure of the device consisted of a $20 \mathrm{~nm} \mathrm{Si}$ doped GaAs cap layer $\left(n=5 \times 10^{18} \mathrm{~cm}^{-3}\right)$, a $20 \mathrm{~nm}$ undoped $\mathrm{Ga}_{0.51} \mathrm{In}_{0.49} \mathrm{P}$ barrier layer, a $20 \mathrm{~nm}$ thick Si doped $\mathrm{Ga}_{0.51} \mathrm{In}_{0.49} \mathrm{P}$ layer $\left(n=3 \times 10^{18} \mathrm{~cm}^{-3}\right)$, a $7 \mathrm{~nm}$ undoped $\mathrm{Ga}_{0.51} \operatorname{In}_{0.49} \mathrm{P}$ spacer layer, a $15 \mathrm{~nm}$ undoped $\mathrm{In}_{0.51} \mathrm{Ga}_{0.85} \mathrm{As}$ channel layer, a $0.2 \mu \mathrm{m}$ GaInP buffer layer and a $0.5 \mu \mathrm{m}$ GaAs buffer layer as shown in Fig. 1. The RIE system was operated at $60 \mathrm{mTorr}$ with a RF power $100 \mathrm{~W}$ and the total flow rate of $\mathrm{BCl}_{3}$ and $\mathrm{Ar}$ was fixed at $10 \mathrm{sccm}$ in

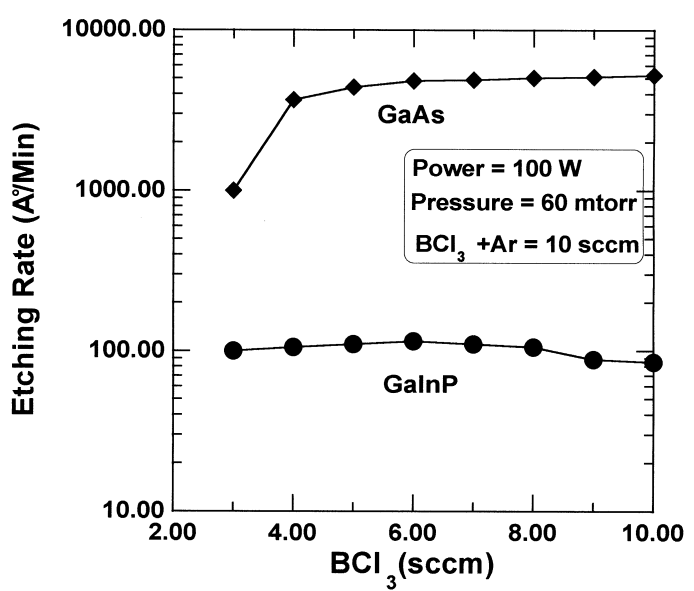

Fig. 2. RIE etching rate vs gas mixing ratio in $\mathrm{BCl}_{3}+\mathrm{Ar}$ gas system.

this study. By increasing the flow rate of $\mathrm{BCl}_{3}$, the etching rate of GaAs increased. These results were consistent with the idea proposed by Seaward et al.[11]. The GaAs etching rate reached as high as $500 \mathrm{~nm} / \mathrm{min}$. These results together with the studies of GaInP can be found in Fig. 2. However, the etching rate of the GaInP film was quite low. The formation of $\mathrm{InCl}_{x}$ prevented the further etching in GaInP and the GaInP etching rate was limited to below $11 \mathrm{~nm} / \mathrm{min}$. The etching selectivity of GaAs to GaInP as a function of $\mathrm{BCl}_{3}$ is shown in Table 1 .

After the $n^{+}$-GaAs cap layer was etched away using the $\mathrm{BCl}_{3} / \mathrm{Ar}$ plasma bombardment, the next step of this study was to characterize the plasmainduced surface damage in the GaInP barrier layer of the QHEMT by Raman spectroscopy. The Raman scattering experiments were demonstrated in backscattering geometry from (100) sample surfaces using an $\mathrm{Ar}^{+}$-ion laser. For III-V compound semiconductors of the zinc-blende crystal structure, Raman spectra in general show two peaks. The lower-frequency peak corresponds to transverse (TO) modes while the higher peak corresponds to longitudinal (LO) modes. In backscattering only LO phonons appear in the (100) backscattering direction and only TO phonons appear in the (110) direction, while both appear in the (111) direction[12]. Figure 3 illustrates InP- and GaP-like LO mode bands at 361.8 and $381.2 \mathrm{~cm}^{-1}$ from an unetched sample[13]. The sharp line at $292 \mathrm{~cm}^{-1}$ corresponds to the GaAs-like LO mode. The three straight lines in Fig. 3 show the disorder-free LO

Table 1. Room temperature GaP-like LO mode shifts toward lower frequency, relative intensity of signal from Raman spectra, surface roughness and the etching selectivity of GaAs to GaInP of different dry-etched and wet-etched QHEMTs

\begin{tabular}{|c|c|c|c|c|c|c|}
\hline & $S_{\text {wet }}$ & $\mathrm{S}_{3: 7}$ & $\mathrm{~S}_{4: 6}$ & $S_{6: 4}$ & $\mathrm{~S}_{8: 2}$ & $\mathrm{~S}_{10: 0}$ \\
\hline Air flow rate $(\mathrm{sccm})$ & wet etched & 7 & 6 & 4 & 2 & 0 \\
\hline $\mathrm{BCl}_{3}$ flow rate $(\mathrm{sccm})$ & & 3 & 4 & 6 & 8 & 10 \\
\hline Surface roughness rms $(\AA)$ & 3.54 & 18.4 & 6.3 & 4.06 & 27.44 & 64.9 \\
\hline The etching selectivity of GaAs to GaInP & 50 & 30 & 37 & 42 & 45 & 47 \\
\hline GaP Raman red shift $\Delta \omega_{\mathrm{LO}}\left(\mathrm{cm}^{-1}\right)$ & 0 & 2.79 & 2.33 & 0 & 3.49 & {$[04.05$} \\
\hline GaP Raman intensity (arb. unit) & 100 & 40 & 45 & 90 & 30 & 25 \\
\hline
\end{tabular}




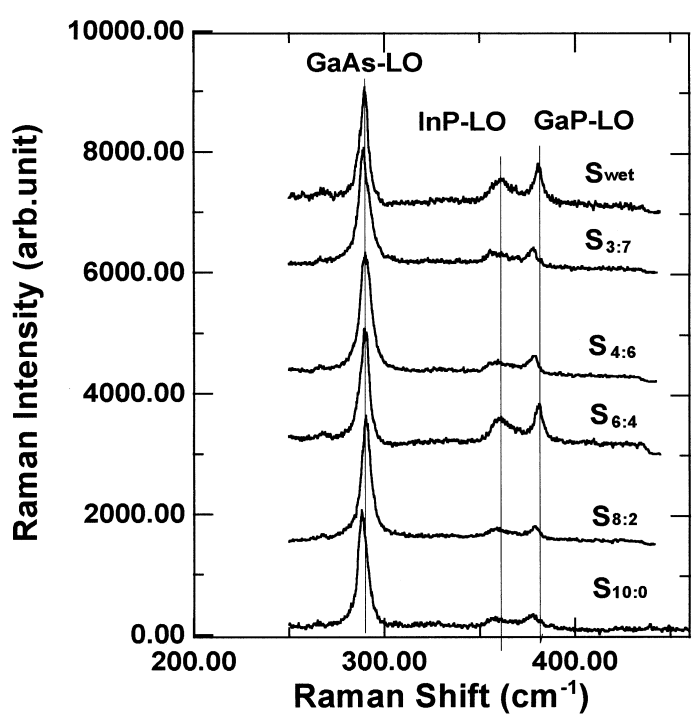

Fig. 3. Raman spectra of different RIE and wet-etched QHEMTs.

mode frequencies. The red shift of the InP and GaP-like LO modes is due to the existence of disordered amorphous-like regions in the surface. The various types of plasma-induced defects result in modification of the LO lattice vibrations[14]. Figure 3 also reveals that the LO mode signals become broader and smaller when the $\mathrm{BCl}_{3} / \mathrm{Ar}$ flow rate ratio differs from $6: 4$. The smaller signal intensity is caused by the lower symmetry of the etched sample which was destroyed by point defects and dislocations during etching[15]. Raman spectrum results show that $\mathrm{RIE}$ with $6: 4 \mathrm{BCl}_{3} / \mathrm{Ar}$ causes minimal damage to the device, resulting in a smooth etched surface similar to a wet etch. Furthermore, AFM was used to determine the plasma-induced surface roughness. Table 1 summar-

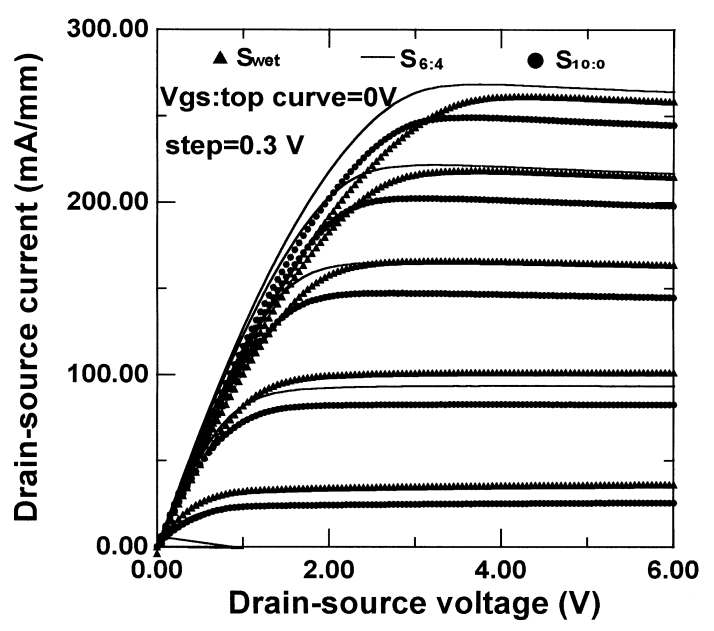

Fig. 4. Drain current-voltage characteristics of wet-etched and dry-etched gate-recess $0.8 \times 50 \mu \mathrm{m}$ PHEMTs. Gate voltage is in $0.3 \mathrm{~V}$ steps and the top curve is $0 \mathrm{~V}$. Wet etched $\left(\mathrm{S}_{\mathrm{wet}}\right)$, dry etched: $\left(\mathrm{S}_{6: 4}\right) \mathrm{BCl}_{3} / \mathrm{Ar}=6 \mathrm{sccm} / 4 \mathrm{sccm}$ $\left(\mathrm{S}_{10: 0}\right) \mathrm{BCl}_{3}=10 \mathrm{sccm}$. izes the various root mean square roughness as a function of different flow rate. It again shows that the flow rate ratio of $\mathrm{BCl}_{3}: \mathrm{Ar}(6: 4)$ has the lowest surface roughness. These results indicate that the conditions for minimum surface roughness, as determined by AFM, correspond with the conditions for minimum plasma damage, as determined by Raman spectroscopy. The reason is that, with pure $\mathrm{BCl}_{3}$, the etching process includes involatile $\mathrm{B}_{2} \mathrm{O}_{3}$ deposition on the etching surface and sidewalls. Thus, the etching surface will be rough. On the other hand, if pure $\mathrm{Ar}$ is used as the etching gas, the etching surface will be severely damaged due to ion bombardment. However, for sample $\mathrm{S}_{6: 4}$, since $\mathrm{Ar}^{+}$can remove the deposited $\mathrm{B}_{2} \mathrm{O}_{3}$, we can achieve a smooth surface and less damage for sample $\mathrm{S}_{6: 4}$.

\section{DEVICE FABRICATION AND CHARACTERIZATION}

In accordance with the results in Section 2, two $\mathrm{BCl}_{3}$ :Ar flow rate ratios, 6:4 (best ratio, as determined by our tests) and 10:0 were used for the gate recessing of the samples used for subsequent comparison. These ratios give a high etching selectivity of $\mathrm{GaAs}$ to GaInP, about 42-47, which ensures that the GaInP layer of the fabricated QHEMTs acts as an etch stop. After RIE, the plasma-etched samples were dipped in $\mathrm{NH}_{4} \mathrm{OH}+\mathrm{H}_{2} \mathrm{O}$ to remove residual oxide and other contamination. Sample $\mathrm{S}_{\mathrm{wet}}$ was prepared by wet etching the $\mathrm{GaAs}$ cap layer in $\mathrm{NH}_{4} \mathrm{OH} / \mathrm{H}_{2} \mathrm{O}_{2} / \mathrm{H}_{2} \mathrm{O}$. After removal of the GaAs cap layer, a $0.8 \mathrm{~m}$ gate metal was deposited on each sample by the lift-off technique. Figure 4 shows the d.c. $I-V$ characteristic of the three fabricated QHEMTs (i.e. $\mathrm{S}_{\text {wet }}, \mathrm{S}_{6: 4}$ and $\mathrm{S}_{10: 0}$ ) prepared by three different etching processes. All samples show good pinch-off characteristics and none of the samples exhibit any "kink effect". However, sample $\mathrm{S}_{6: 4}$, dry etched with a $6 \mathrm{sccm} \mathrm{BCl}_{3}$ flow rate, a $4 \mathrm{sccm}$ Ar flow rate and a $100 \mathrm{~W}$ RF power, has the highest drain-source saturation current $\left(I_{\mathrm{dss}}\right)$. The transconductance $\left(g_{\mathrm{m}}\right)$ values of the three fabricated QHEMTs are plotted in Fig. 5. It can be seen that sample $\mathrm{S}_{6: 4}$ has the highest $g_{\mathrm{m}}$ value among the four samples. The maximum $g_{\mathrm{m}}$ of the wet-etched sample $S_{\text {wet }}$ is smaller than that of sample $S_{6: 4}$. This is probably due to the decrease in source resistance as a result of the elimination of the undercut[16] and the tighter gate recess[17] for sample $S_{6: 4}$. Samples etched with pure $\mathrm{BCl}_{3}$ (i.e. sample $\mathrm{S}_{10: 0}$ ) will result in a smaller $g_{\mathrm{m}}$ due to the increase of surface damage. These results were confirmed by $C-V$ measurements. Figure 6 shows the $C-V$ characteristics of three QHEMTs prepared by different etching processes. It can be seen that, relative to the $\mathrm{S}_{\text {wet }} C-V$ curve, the sample $\mathrm{S}_{6: 4}$ has no significant positive voltage shift and the sample $S_{10: 0}$ has a $0.5 \mathrm{~V}$ positive voltage shift. The positive shift is due to negative charges such as compensation centers, 


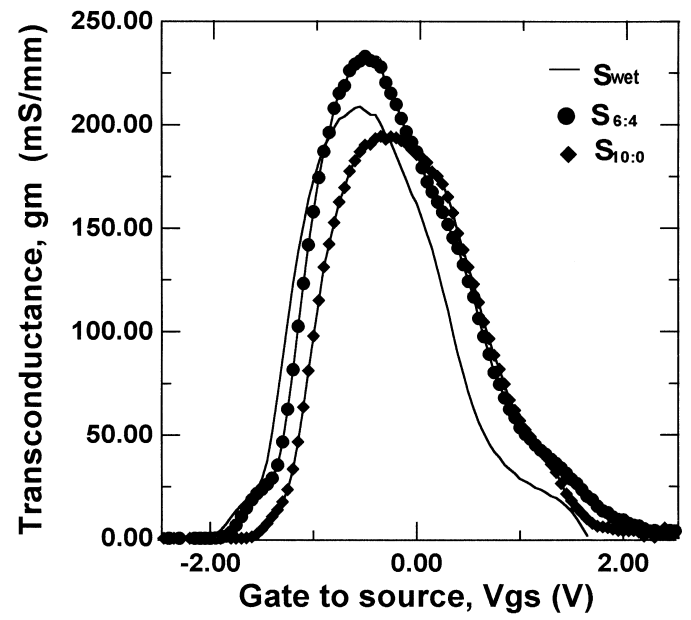

Fig. 5. Comparison of extrinsic transconductance $\left(g_{\mathrm{m}}\right)$ between different RIE and wet-etched QHEMTs.

which result from plasma-induced damage[18]. From the above results, it is clear that the sample $\mathrm{S}_{6: 4}$ has smooth etched surfaces (similar to wet etch) while the plasma-induced surface damage is much more serious for samples $\mathrm{S}_{10: 0}$.

Figure 7 shows a histogram of threshold voltage for the dry-etched and wet-etched devices. The mean threshold voltages for these QHEMTs are $-1.425,-1.377$ and $-0.965 \mathrm{~V}$ for samples $\mathrm{S}_{\text {wet }}, \mathrm{S}_{6: 4}$ and $\mathrm{S}_{10: 0}$, respectively. The standard deviation of the wet-etched devices $S_{\text {wet }}$ is $110 \mathrm{mV}$, whereas samples $\mathrm{S}_{6: 4}$ and $\mathrm{S}_{10: 0}$ show significantly lower values of 48 and $92 \mathrm{mV}$, respectively. The threshold voltage uniformity of sample $\mathrm{S}_{6: 4}$ was found to be better than that of sample $S_{10: 0}$ and sample $S_{w e t}$.

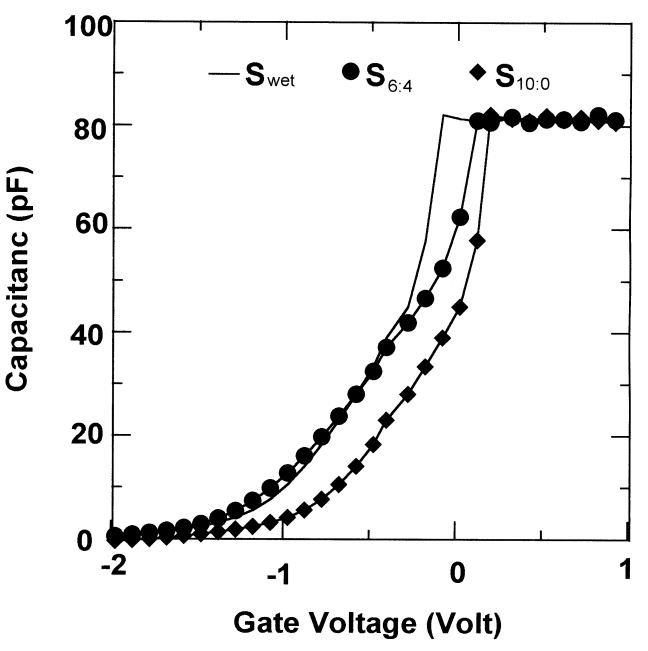

Fig. 6. Extracted gate-source capacitance $\left(C_{\mathrm{gs}}\right)$ of different RIE and wet-etched QHEMTs as a function of gatesource voltage.

\section{CONCLUSIONS}

The best $\mathrm{BCl}_{3} / \mathrm{Ar}$ gas flow ratio for minimumdamage RIE gate recessing of a GaInP/InGaAs/ GaInP quantum well HEMT (QHEMT) was determined to be $6: 4$ at this study. Raman spectroscopy was shown to be able to characterize the near surface damage done to the barrier layer of our QHEMTs. Our results show that Raman spectroscopy is powerful and nondestructive measurement tool for characterizing plasma-induced surface damage and can be used to improved the performance of QHEMTs. The best $\mathrm{BCl}_{3} / \mathrm{Ar}$ gas flow ratio as determined here was used to etch the gate recess in $\mathrm{GaInP} / \mathrm{InGaAs} / \mathrm{GaInP}$ QHEMTs. From $C-V$ measurement, it is clear that the sample $\mathrm{S}_{6: 4}$ has a smooth etched surfaces (similar to a wet etch) while

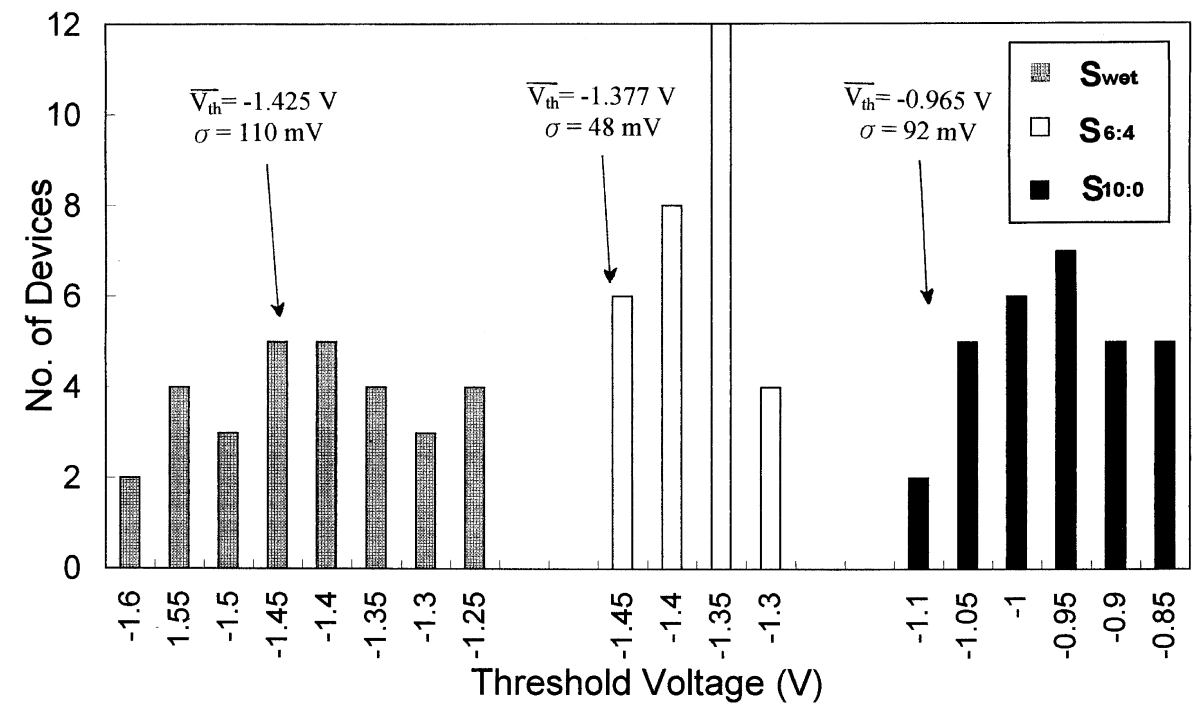

Fig. 7. Histograms of the threshold voltages for GaInP/InGaAs/GaInP QHEMTs with $0.8 \mu \mathrm{m}$ gate lengths. 
the plasma-induced surface damage is much more serious for samples $\mathrm{S}_{10: 0}$. Comparison testing of our RIE-fabricated and wet-etch-fabricated QHEMTs showed that the d.c. characteristics of the sample $\mathrm{S}_{6: 4}$ were superior to those of the wet-etched devices and sample $\mathrm{S}_{10: 0}$. In addition, the threshold voltage uniformity of sample $S_{6: 4}$ was found to be better than that of $S_{10: 0}$ and $S_{w e t}$.

Acknowledgements - The authors gratefully acknowledge the technical contributions of Dr H. H. Lin and Dr M. C. Lee, This work was performed at the National Cheng Kung University and was supported by National Science council under contract number NSC 86-2732-E-006-006R.

\section{REFERENCES}

1. Takamiya, S., Yoshida, N., Hayafuji, N., Sonoda, T. and Mitsui, S., Solid-St. Electron., 1995, 38, 1581.

2. Chan, Y.-J., Pavlidis, D. and Razeghi, M., IEEE Trans. Electron Device, 1990, 37, 2141.

3. Takikawa, M. and Joshin, K., IEEE Electron Device Lett., 1993, 14(8), 406.

4. Pang, S. W., Goodhue, W. D., Lyszezarz, T., Ehrlich, D. J., Goodman, R. B. and Johnson, G. D., J. Vac. Sci. Technol. B, 1988, 6, 1916.

5. Clausen, E. M., Craighead, H. G., Harbison, J. P., Scherer, A., Schiavone, L. M., Van der Gaag, B. and Florez, L. T., J. Vac. Sci. Technol. B, 1989, 7, 2011
6. Cooperman, S. S., Choi, H. K., Sawin, H. H. and Kolesar, D. F., J. Vac. Sci. Technol. B, 1989, 7, 41.

7. Hong, J., Lee, J. W., Santana, C. J., Abernathy, C. R., Pearton, S. J., Hobson, W. S. and Ren, F., Semicond. Sci. Technol., 1996, 11, 1218.

8. Su, Y. K., Juang, Y. Z., Shei, S. C. and Fang, B. C., Solid-St. Electron., 1993, 36(12), 1779.

9. Tsang, J. C., Oehriein, G. S., Haller, I. and Custer, J. S., Appl. Phys. Lett., 1985, 46, 589.

10. Duran, H. C., Patrik, W. and Bachtold, W., J. Vac. Sci. Technol. B, 1995, 13, 2386.

11. Pollak, F. H., Microelectronics: Applications, Materials and Technology, Vol. 185. SRI International, Menlo Park, CA, 1984.

12. Rama Rao, C. S., Sundaram, S., Schmidt, R. L. and Comas, J., J. Appl. Phys., 1983, 54, 1808.

13. Fan, R., Stephen, J. P., Cammy, R. A., Chan, S. W. $\mathrm{Hu}$, M., Pao, C. K., Wang, D. C. and Wen, C. P., IEEE Trans., 1992, 39, 2701.

14. Jiang, G. C., Jpn. J. Appl. Phys., 1996, 35(Pt.1), 533.

15. Su, Y. K. and Gan, K. J., J. Appl. Phys., 1990, 68, 5584.

16. Agrawala, S., Nummila, K., Adesia, I., Caneau, C. and Bhat, R., IEEE Electron Device Lett., 1993, 14, 425.

17. Duran, H. C., Klepser, B.-U. H. and Bachtold, W. IEEE Electron Device Lett., 1996, 17, 482.

18. Agarwala, S., Tong, M., Ballegeer, D. G., Nummila, K., Ketterson, A. A. and Adesida, I., J. Electron. Mater., 1993, 22, 375. 